\title{
Instituições, Direito e Soberania: a efetividade jurídica nos processos de integração regional nos exemplos da União Européia e do Mercosul
}

\author{
Institutions, Law and Sovereignty: a legal effectiveness \\ in the processes of regional integration of European Union \\ and the Mercosur
}

PATRÍCIA LUÍZA KEGEL* MOHAMED AMAL**

Rev. Bras. Polít. Int. 52 (1): 53-70 [2009]

\section{Introdução}

No âmbito dos processos de integração regional, a construção de um arcabouço normativo proveniente dos órgãos conjuntos de integração, apresentou, desde o início, características próprias quanto à implementação de suas normas no espaço territorial dos Estados. Mais especificamente, tem sido necessário definir um tipo diferenciado de articulação desta nova "ordem jurídica" com os distintos ordenamentos jurídicos nacionais, baseados no princípio tradicional da soberania do Estado. Neste sentido, a efetividade do conjunto de normas destinado a implementar os objetivos do acordo de integração depende, em grande medida, de sua receptividade nos sistemas jurídicos nacionais. Tal constatação refletiu-se na necessidade de desenvolver um mecanismo original de coexistência entre a ordem jurídica destinada a normatizar o processo de integração regional e os direitos nacionais.

A crescente importância das instituições na definição e no alcance do desenvolvimento econômico de um determinado país ou região constituirá o contexto teórico deste trabalho, que tem por objetivo analisar e discutir determinadas questões provenientes desta nova configuração de relacionamento entre distintas ordens normativas, sob a perspectiva da eficácia das instituições jurídicas de integração para alcançar os objetivos desejados.

\footnotetext{
* Professora de Direito Internacional e Globalização no Programa de Pós-Graduação em Desenvolvimento Regional na Universidade Regional de Blumenau - FURB (paluke@furb.br).

** Professor de Economia Internacional no Departamento de Economia e Programa de Pós Graduação em Administração da Universidade Regional de Blumenau -FURB (amal@furb.br).
} 
Após a delimitação do marco conceitual, serão inicialmente examinadas as relaçōes entre Direito nacional e o Internacional Público, formatadas sob a égide da soberania dos Estados, tal qual expressa em suas Constituições nacionais. Em um segundo momento, serão dispostos os elementos comuns a este novo tipo de articulação entre ordenamentos jurídicos e posteriormente será abordada a dinâmica da coexistência entre distintas ordens jurídicas na União Européia e no Mercosul. Por último, as considerações finais remetem à necessidade de repensar a soberania nos processos de integração regional, sob a perspectiva da eficácia de seu ordenamento jurídico para alcançar o conjunto dos objetivos desejados.

\section{Instituições, desenvolvimento econômico e integração regional}

Para a teoria econômica neoclássica, o equilíbrio numa economia e as variáveis econômicas relevantes, tais como preços e produtos, podem ser explicados apenas por si mesmos. Nesta perspectiva, o desenvolvimento econômico e a inserção competitiva internacional de um determinado país ou região têm sido habitualmente vistos sob a ótica das condições macroeconômicas. Fatores como tamanho e crescimento do mercado, disponibilidade do fator trabalho e seus custos, níveis de inflação e de endividamento externo e a situação do balanço de pagamentos foram sempre considerados os principais indicadores de desenvolvimento econômico e do grau de atratividade para projetos de investimento internacional e comércio.

Deste modo, as variações das estruturas institucionais entre países ou regiōes integradas foram simplesmente desconsideradas ou tratadas apenas como fatores secundários. No entanto, a evolução das teorias econômicas vem apontando para a importância crescente do quadro institucional na definição do desempenho econômico. Ou seja, a eficiência dos sistemas jurídico, político e administrativo tornou-se essencial para determinar o grau de desenvolvimento econômico, e impôs a análise do papel das instituições e seu impacto, como um dos fatores chave para apresentar elementos de explicação das diferenças nas taxas de crescimento e renda per capita entre os países.

Por "instituições" compreende-se um conjunto normativo orientado a determinados objetivos e os instrumentos que garantam sua execução, para dirigir o comportamento individual em determinada direção. Neste contexto, o trabalho de North é fundamental para entender a relação entre mudança institucional e desenvolvimento econômico ${ }^{1}$. Segundo este autor, as instituições devem ser entendidas como sendo as regras do jogo, ou seja, são as restriçōes criadas pela sociedade e que constituem a forma por meio da qual ocorre a interação de seus membros. Sua função é reduzir a incerteza, ao proporcionar uma estrutura à vida

1 NORTH, Douglass C. Institutiones, Cambio Institucional Y Desempenõ Econômico. Traducción de Agustín Bárcena. México: Fondo de Cultura Econômica, 1993. 
cotidiana, definindo e limitando o conjunto de escolhas dos indivíduos. Assim, a eficiência dos mercados depende das instituições de suporte capazes de definir e fornecer regras formais e informais de jogo para o seu funcionamento, ocupando um lugar central na análise do processo de desenvolvimento econômico.

Na perspectiva da Teoria Neo-institucional, a Teoria Econômica do Direito oferece um quadro de análise das instituições jurídicas, no qual estuda o impacto do sistema normativo sobre o comportamento dos agentes econômicos e sua repercussão sobre preços e quantidades de bens e serviços, tendo por objetivo a eficiência na maximização da riqueza ${ }^{2}$. Seu fundamento está na concepção de que o "mercado" é uma criação essencialmente jurídica, consistindo em uma série de normas gerais, que permitem que potenciais compradores ou vendedores de bens ou serviços entrem em contato entre si, com o objetivo de comerciar. Em sua acepção mais ampla, tais normas são essencialmente as que definem os direitos de propriedade sobre os ativos tangíveis e intangíveis (direitos reais e direitos de propriedade intelectual), as que estabelecem o modo de celebração de contratos e as obrigações decorrentes dos mesmos e as normas de responsabilidade civil extracontratual, complementares a estas últimas nas hipóteses em que se produzem relações entre agentes econômicos que não surjam de um contrato ${ }^{3}$.

Neste sentido, as instituiçõos em geral, e as jurídicas em particular, são essenciais para a redução dos custos de transação e do grau de incerteza e instabilidade das sociedades e economias ${ }^{4}$. Ou seja, instituições jurídicas debilitadas afetam profundamente o desenvolvimento econômico, pois reduzem a segurança jurídica, aumentam a incerteza e os riscos, terminando por comprometer o planejamento de agentes privados, bem como as demais instituições.

No quadro deste enfoque institucional de análise, a organização internacional resultante de acordos de integração regional pode ser definida, como sendo uma associação voluntária de Estados, dotada de órgãos permanentes, próprios e independentes, encarregados de administrar os interesses coletivos e capazes de expressar uma vontade juridicamente distinta da de seus membros 5 . Desta forma, as decisões adotadas nas instâncias criadas para administrar o acordo, passam a substituir as instâncias nacionais correspondentes, nas áreas em que o Tratado Constitutivo reservou para as competências conjuntas. Consequentemente, a base normativa que orienta o processo de tomada de decisóes e possibilita a previsibilidade de atuação à médio e longo prazos, deixa de derivar dos governos nacionais e passam a estar vinculada às instâncias conjuntas. Neste sentido, o debate

2 COLlONA, German. Analisis Economico del Derecho. Buenos Aires : Ciudad Argentina, 2001, p.12.

3 COLONNA, op.cit., p.19.

4 Os custos de transação são custos para descobrir os preços relevantes, negociar, concluir e impor contratos, de informação, etc. e são influenciados pelo "ambiente institucional" e pelo conjunto de atributos que afetam a tomada de decisóes.

5 VELASCO, Manuel Diez de. Las Organizaciones Internacionales. Madrid : Tecnos, 1995, p.37. 
sobre a eficiência das instituições jurídicas em processos de integração regional, torna-se essencial para o sucesso de projetos conjuntos de desenvolvimento.

No contexto da integração regional, situam-se dois grandes modelos institucionais, o supranacional correspondente à experiência da União Européia, e o intergovernamental, utilizado, com variantes, por todos os demais blocos econômicos e pelo Mercosul em particular. A União Européia é jurídica e politicamente caracterizada pela supranacionalidade, sendo sua contraface econômica, uma união econômica e monetária, com a instituição de um mercado interno e de uma moeda única (mesmo que nem todos os Estados-membro tenham tomado o Euro como moeda). Já o Mercosul adotou o padrão intergovernamental clássico para organizar sua estrutura institucional, mantendo nos seus Estados-parte todo o controle do processo decisório, o qual necessita de consenso para gerar qualquer tipo de decisão. Quanto à sua profundidade, o Mercosul encontra-se no estágio de uma "União Aduaneira em implantação", traduzindo a dificuldade de consolidação da zona de livre comércio e a constante perfuração da Tarifa Externa Comum. No entanto, tal situação não impede, ou não deveria impedir, a progressiva formação de uma política comercial comum correspondente à união aduaneira. Adotando o pressuposto de que o estabelecimento de blocos de integração regional é um dos elementos de estímulo à atividade econômica, efetuaremos a seguir uma comparação entre a União Européia e o Mercosul quanto à eficiência de suas respectivas estruturas jurídicas para a implementação das normas comunitárias ${ }^{6}$.

\section{Direito e Integração Regional ${ }^{7}$}

Sob uma perspectiva qualitativa, a maior diferença entre um Mercado Comum e as etapas anteriores da integração regional, Zona de Livre Comércio e União Aduaneira, reside, em grande medida, na circunstância de que o Mercado Comum não se restringe apenas ao livre acesso a mercados. Ou seja, deve garantir a livre circulação de produtos e fatores produtivos, independentemente das diversas normas nacionais que regulem a atividade econômica, como por exemplo, padrōes técnicos ou sanitários, de forma a permitir equiparação de concorrência na oferta de produtos e serviços no mercado integrado. Este aprofundamento torna imperiosas medidas de aproximação legislativa, o reconhecimento mútuo de especificações nacionais, assim como uma normatização comum sobre concorrência. Etapas de integração negativa tais como a eliminação das barreiras ao comércio, devem ser complementadas por etapas de integração positiva, em especial a harmonização de padrōes técnicos, normas de defesa do consumidor e legislação ambiental.

6 Nos limites deste trabalho, o termo "comunitário" é utilizado para adjetivar os elementos decorrentes de qualquer processo de integração regional, tanto o supranacional europeu, quanto os demais.

7 A expressão "integração regional" refere-se de forma geral a processos de integração economica e cooperação entre Estados, de intensidade e objetivos distintos. 
O objetivo principal, portanto, é garantir a liberdade e a igualdade das condições de concorrência ao diminuir as distorçôes do mercado ampliado.

Acordos de integração regional dão origem a organizações internacionais destinadas a implementar a cooperação econômica, comercial e, eventualmente, política, consideradas como objetivo principal do acordo. Em seu âmbito, são criadas estruturas institucionais destinadas a administrar o processo propriamente dito. Dependendo da profundidade da integração desejada, o ambiente jurídico e institucional criado para gerenciar a implantação e o desenvolvimento dos objetivos acordados, poderá ser mais ou menos intenso. Desta forma, a Zona de Livre Comércio e a Uniāo Aduaneira, por serem menos ambiciosas, podem manter um quadro meramente intergovernamental. No entanto, um Mercado Comum, necessita de mecanismos supranacionais, que garantam a instituição de um espaço econômico mais integrado. Neste sentido, os sistemas intergovernamental e supranacional são expressões institucionais e jurídicas das diversas formas de integração regional.

No caso das organizações intergovernamentais, sua estrutura, composição de seus órgãos, âmbito de competências e sistema decisório, são geridos por formas tradicionais do Direito Internacional Público (DIP), baseadas no principio da igualdade soberana entre os Estados e não ingerência em seus assuntos internos. A adoção de decisões da organização é efetuada por órgãos compostos por representantes dos governos, que são designados por estes e sujeitos às suas instruções. Utiliza-se a regra de unanimidade quando as decisões possuem efeito vinculante e, principalmente, a eficácia das decisões é mediata, ou seja, qualquer decisão adotada pela Organização deve ser executada pelos próprios Estadosmembro para que possa produzir efeitos na sua ordem jurídica interna. Este desenho institucional corresponde, com algumas variantes e com exceção da União Européia (UE), a todos os demais processos de integração regional.

Por sua vez, a supranacionalidade comunitária destaca a especificidade institucional e jurídica do processo de integração europeu. Não existe uma definição unívoca de supranacionalidade, a qual designa um novo tipo de organização internacional, em que os Estados-membro não se encontram mais em situação de absoluta igualdade, é permitida a ingerência em seus assuntos internos e a relação entre a organização e os Estados deixa de ser de coordenação e passa a ser de subordinação destes àquela. $\mathrm{O}$ resultado consiste em uma transferência substancial de competências legislativas, executivas e judiciárias por parte dos Estados em favor da organização.

Desta forma, dependendo da intensidade pretendida, o arcabouço jurídico elaborado para normatizar as relações surgidas no interior do bloco será mais ou menos sofisticado, ou seja, poderá ser tanto mais específico e autônomo em relação ao DIP, quanto mais aprofundado seja o processo de integração. Tal especificidade se manifesta particularmente nas relaçóes entre este novo ordenamento jurídico e os ordenamentos jurídicos nacionais. Neste caso, não se utilizam mais as categorias 
tradicionais de relacionamento entre Estados, porém um tipo diferenciado. Quanto mais supranacional e, portanto, com mais âmbitos de soberania compartida ou de cessão de direitos de soberania, mais peculiar será o arcabouço jurídico deste tipo de interação.

\section{Soberania, Direito Internacional e Constituição}

A tendência para a formação de espaços regionais integrados tem alterado o eixo da discussão jurídica. As categorias tradicionais utilizadas tanto pelo Direito Internacional Público quanto pelo Direito Constitucional, tornaram-se insuficientes para explicar e, sobretudo, organizar as relações entre Estados surgidas no interior de um processo de integração regional. $\mathrm{O}$ aparato constitucional tradicionalmente utilizado pelos Estados para regulamentar sua atuação no sistema internacional, apresentou limites de ordem conceitual e procedimental para ordenar as relações intra-regionais. Neste sentido, torna-se imperioso debater a extensão de conceitos fundamentais da Teoria Geral do Estado e da Teoria Constitucional, tais como soberania e supremacia constitucional, com o objetivo de permitir a abertura dos sistemas jurídicos nacionais às normas externas. Nas próximas seções serão abordadas as relações tradicionais entre Estados soberanos e Direito Internacional, bem como as peculiaridades da Teoria Jurídica nos processos de integração regional.

\section{Os Estados e o atributo da soberania}

A questão envolvendo a soberania estatal surgiu a partir de meados da Idade Média, no bojo da luta desenvolvida pelos Estados territoriais contra as renovadas pretensōes de suserania do Sacro Império e contra o exercício do poder temporal pelo papado. A partir dos séculos XIII e XIV desenvolveu-se a tese de que o senhor local seria um suserano não submetido a nenhum outro poder, sendo este movimento rumo à autonomia em relação ao Império e ao papado indispensável ao processo de formação dos Estados modernos. Mas é apenas a partir de Bodin que a soberania constitui-se como elemento decisivo dos atributos do poder de Estado. Neste sentido, sua teoria sustenta que a essência do Estado é a unidade do poder, a qual transforma uma simples associação de seres humanos em entidade estatal e implica o poder discricionário que o soberano exerce sobre o conjunto de instrumentos normativos que coordenam o convívio social em direção a uma sociedade juridicamente organizada.

Desde a Paz da Westfália, a soberania possui uma origem e finalidade políticas tanto no âmbito interno quanto externo. Externamente, a soberania confere aos Estados um poder que não admite subordinação a nenhum outro poder, mas que é compartido por outros Estados soberanos, atores das relações internacionais e sujeitos de Direito Internacional. Internamente, confere à autoridade na qual está 
fundamentada (o príncipe, uma assembléia, o povo ou nação) um poder absoluto, supremo, o qual subordina as demais vontades e exclui a competência de qualquer outro poder similar.

Superada a fase da identificação entre o soberano e o Estado (l'état c’est moi), a teoria democrática situa no povo o detentor da soberania do Estado, cuja maior expressão jurídica é o Poder Constituinte. Esta tese remonta, sob o ponto de vista histórico, às doutrinas contratualistas de cunho liberal, segundo as quais a origem da sociedade e o fundamento do poder político, estariam em um contrato que fosse a expressão do consenso da maioria dos indivíduos ${ }^{8}$. Assim, a fonte final do poder legiferante do Estado é o povo, motivo pelo qual é o único detentor legítimo do Poder Constituinte9.

Deste modo, o conceito de soberania que originalmente possui um conteúdo fático vinculado às suas origens políticas e internacionais, é posteriormente recepcionado como atributo jurídico nacional, onde significará a supremacia do poder interno e a fonte de legitimidade do poder político, expressas no primado absoluto da Constituiçãao ${ }^{10}$. Juridicamente, portanto, a soberania interna significa que no território do Estado a Constituição é suprema e apenas as normas elaboradas pelo legislador nacional, ou as que por ele forem reconhecidas como tal, são válidas.

\section{Constituição e Direito Internacional}

As respostas que o Direito Constitucional fornece ao convívio entre Estados, vêm sendo elaboradas desde o início mesmo do Direito Internacional. Em especial os três aspectos seguintes são relevantes na articulação de ambas as ordens jurídicas, e que se manifestarão também nos processos de integração regional.

a) se as normas de Direito Internacional são de aplicação imediata no âmbito interno dos Estados, ou se é necessária alguma norma nacional que integre a norma internacional ao sistema jurídico nacional;

b) qual sua posição hierárquica dentro do ordenamento jurídico nacional. $\mathrm{Ou}$ seja, caso haja conflito entre uma norma internacional e outra nacional, a quem caberá a primazia;

c) o controle da constitucionalidade da norma internacional perante as Constituiçôes Nacionais.

\footnotetext{
8 As teorias contratualistas dos século XVIII consideram o Estado decorrente de um contrato social de cada um com todos os outros, sobre um conjunto de princípios fundamentais. Assim, o fundamento de legitimidade do poder político reside na soberania do povo, que expressa um contrato entre iguais. Sob a perspectiva jurídica, foi o Abade Sieyès que, ao efetuar a diferenciação entre Poder Constituinte e Poder Constituido, possibilitou a concepção da superioridade formal da Constituição sobre as demais normas.

9 Importa sublinhar o fato de que a experiência histórica afirma ser o povo o único detentor legítimo do Poder Constituinte, mas não o único a exercer efetivamente tal poder.
}

10 VIGNALI, Heber Arbuet. Derecho Internacional Publico. Temas de la Teoria General. Santa Fé: Universidad Nacional del Litoral, 1996, p.17. 
Em relação ao primeiro aspecto, uma das principais diferenças entre o Direito Internacional e a ordem jurídica interna, repousa no seu fundamento de validade. O Direito interno é válido em virtude da vontade do legislador nacional como expressão jurídica da soberania interna, enquanto o Direito Internacional possui sua validade decorrente do consenso entre Estados soberanos e Organizaçóes Internacionais.

Para a teoria monista, Direito Internacional e Direito Nacional são subsistemas de um único ordenamento jurídico, porém com distintos âmbitos de incidência. Neste caso, não existe necessidade de ato complementar para que uma norma internacional tenha validade interna. Já para a teoria dualista, Direito Internacional e Direito Nacional formam ordens jurídicas separadas, sem contato entre si. Para que uma norma internacional tenha validade no âmbito jurídico interno, será necessário incorporá-la ao sistema jurídico nacional.

Para além do debate teórico, a prática tem demonstrado que as normas internacionais não possuem validade imediata na ordem jurídica interna dos Estados. A influência da ordem jurídica internacional sobre a nacional necessita, portanto, de um ato suplementar, por meio do qual se possibilita a abertura da soberania dos Estados em relação ao Direito Internacional. Para que as normas internacionais possuam validade na ordem jurídica interna, elas devem converterse em normas nacionais, por um procedimento de transformação específico, que lhes confere novo fundamento de validade e novos destinatários.

Por sua vez, a estrutura hierárquica das normas no interior de um sistema jurídico está elaborada de acordo com princípios de validade e procedimento. A Constituição possui a posição mais elevada, e o sistema como um todo está de tal forma articulado que, na hipótese de conflito, a norma superior derroga a norma inferior, e a posterior derroga a anterior ${ }^{11}$. Uma vez válida a norma internacional dentro do sistema jurídico interno, está aberta a possibilidade de conflito com uma norma nacional. Neste caso, a primazia dependerá da posição hierárquica da norma internacional, a qual poderá ser incorporada entre um amplo espectro hierárquico, que vai desde Lei Complementar (subordinada apenas à Constituição e sem poder ser alterada pelo legislativo nacional), até Lei Ordinária (a qual pode ser modificada por qualquer lei posterior), passando por inúmeras variaçóes nacionais.

Por último, como a Constituição é a expressão do Poder Constituinte, ela encontra-se no ápice do sistema jurídico nacional, e todas as demais normas lhe estão subordinadas. Esta conformação dos sistemas jurídicos nacionais em uma pirâmide tanto mantém a legitimidade do sistema, quanto sua coerência interna. A norma internacional incorporada deverá ser compatível com a Constituição e, deste modo, sofrer seu controle de constitucionalidade. Se for considerada incompatível, ela será declarada nula e não produzirá efeitos.

11 De acordo com critérios generalizados de solução de antinomias jurídicas, "lex superior derogat legi inferior" e "lex posterior derogat legi anterior. 
É importante observar que caso não cumpra com suas obrigações internacionais, o Estado pode incorrer em responsabilidade, ou seja, vir a sofrer alguma sanção por parte dos demais Estados celebrantes de um tratado ou integrantes de uma organização internacional. Assim, caso uma norma internacional venha a ser derrogada por outra lei nacional posterior, ou se um juiz declarar inaplicável a norma internacional em virtude de sua inconstitucionalidade, este Estado estará incorrendo em responsabilidade internacional, não importando quais sejam suas considerações constitucionais de ordem interna ${ }^{12}$.

\section{Direito e Ordenamento Jurídico dos Processos de Integração}

É extremamente importante salientar que não existe uma teoria jurídica que conceitualize o conjunto das relações entre o direito dos processos de integração e os ordenamentos jurídicos nacionais. Por um lado, porque as diferenças entre o sistema supranacional e o intergovernamental dificultam a elaboração de uma tipologia única de conceitos. Por outro, porque o fenômeno da integração regional é relativamente recente, e desta forma, ao contrário do Direito Internacional tradicional, a formação das categorias destinadas a coordenar este novo tipo de interpenetração de distintas ordens jurídicas, ainda encontra-se em elaboração ${ }^{13}$.

De modo geral, o Direito emanado dos processos de integração regional, é dividido em Direito Primário e Direito Secundário. Por Direito Primário, entendem-se os Tratados Constitutivos e suas alterações. Por Direito Secundário, as normas editadas pelos órgãos de integração, no exercício de suas competências executiva, legislativa e jurisdicional. Em relação aos três aspectos anteriormente citados, as soluçôes tradicionais tornaram-se insuficientes e desenvolveram-se mecanismos diferenciados para conciliar o ordenamento jurídico nacional com a nova realidade da integração.

Em relação à aplicabilidade da norma comunitária nos sistemas jurídicos acionais, existem as seguintes possibilidades:

- Aplicabilidade mediata absoluta: a norma comunitária necessita sempre de um ato interno de incorporação para que possa produzir qualquer tipo de efeito na ordem jurídica nacional. Neste caso, não existe diferença quanto à norma comunitária e a internacional.

- Aplicabilidade mediata moderada: dependendo do tipo de norma comunitária, será ou não necessário um ato interno de incorporação. Assim, a norma comunitária cuja incidência ocorre exclusivamente no âmbito do Poder Executivo, possui aplicabilidade imediata. Já a norma comunitária,

12 De acordo com o diposto no art. 27 da Convenção de Viena sobre o Direito dos Tratados entre Estados e Organizações Internacionais (1986): "Um Estado-Parte de um Tratado não pode invocar as diposiçôes de seu direito interno para justificar o inadimplemento de um Tratado".

13 O que não impede que cada processo de integração regional conte com teóricos aptos a refletir e sistematizar seu Direito Comunitário. 
que de alguma forma altere a ordem jurídica vigente, necessita de um ato do Legislativo nacional para sua incorporação.

- Aplicabilidade imediata absoluta: a norma comunitária entra diretamente na ordem jurídica interna dos Estados, sem necessidade de qualquer ato de incorporação.

- Aplicabilidade imediata moderada: a norma comunitária determina expressamente que deverá ser incorporada.

Por sua vez, a posição hierárquica do direito emanado dos órgãos de integração regional dentro dos sistemas jurídicos nacionais pode ser a seguinte:

- Hipótese supranacional: a norma comunitária, tanto primária quanto secundária, é superior à Constituição dos Estados e seus ordenamentos jurídicos. Não pode ser modificada por nenhuma lei nacional anterior ou posterior.

- Hipótese supralegal: quando as normas comunitárias são superiores ao conjunto das leis do Estado, mas não à Constituição. Neste caso, a norma comunitária não poderá ser contrária à Constituição, mas uma vez considerada constitucional, não poderá ser alterada por nenhuma norma nacional posterior, a não ser por uma alteração constitucional.

- Hipótese legal: quando a norma comunitária não possui posição hierárquica definida, é incorporada mediante procedimento ordinário e pode ser alterada por uma lei nacional posterior (mesmo que depois o Estado responda pelos prejuízos causados).

E, por fim, o controle da constitucionalidade da norma comunitária talvez seja o aspecto mais controverso e de difícil equacionamento nas relaçôes entre ambas as ordens jurídicas. A renúncia à verificabilidade da norma comunitária, em especial da norma derivada, à Constituição nacional, tem exigido prodígios de hermenêutica constitucional e abertura ao sistema jurídico comunitário. Neste item apresentam-se três possibilidades:

- Renúncia total: Órgãos jurisdicionais singulares e Cortes Constitucionais, abdicam do controle da conformidade da norma comunitária, primária e secundária, à Constituição Nacional.

- Renúncia parcial: apenas as Cortes Constitucionais mantém a possibilidade de efetuar o controle da constitucionalidade da norma comunitária. Os órgãos jurisdicionais singulares perdem tal competência

- Controle total: o conjunto do Poder Judiciário nacional mantém intacta sua competência para efetuar o controle da constitucionalidade da norma primária e secundária. Significa, por exemplo, que uma norma comunitária emanada tanto dos Tratados Constitutivos quanto dos órgãos decisórios conjuntos, poderia ter sua inconstitucionalidade argüida perante qualquer juízo singular ou colegiado.

Nas próximas seções serão abordadas as experiências supranacional e intergovernamental de inter-relacionamento entre ordenamentos jurídicos distintos, 
com o objetivo de analisar em que medida cada um apresenta respostas e limites às tensões entre soberania e instituições na dinâmica da integração.

\section{Direito nacional, Supranacionalidade e Direito Comunitário Europeu ${ }^{14}$}

Como bem sublinhado por Bleckmann, desde seu início o Direito Comunitário Europeu não se constituiu em Direito Internacional Público no sentido tradicional do termo ${ }^{15}$. Ou seja, não formou um conjunto jurídico que possuísse seu fundamento de validade nos mesmos critérios que regem a produção de normas de Direito Internacional. A conseqüência mais importante desta linha de raciocínio reside na afirmação de que o Direito comunitário primário não é mais Direito Internacional. Ao contrário, trata-se de um Direito com dupla natureza, que concomitantemente possui um caráter constitucional, aliado ainda aos aspectos internacionais provenientes de suas origens nos Tratados Constitutivos ${ }^{16}$. Frente ao silêncio normativo, os conflitos de articulação entre as ordens jurídicas nacionais e a comunitária foram resolvidos, de forma pretoriana, pelo Tribunal de Justiça das Comunidades Européias (TJCE) ${ }^{17}$. O resultado foi uma estrutura jurídica inédita no histórico das relações entre Estados, baseada nas seguintes características.

Inicialmente, a aplicabilidade imediata da norma comunitária, em especial de Regulamentos e Decisões ${ }^{18}$, a qual dispensa a interposição legislativa nacional para integrar-se ao ordenamento jurídico dos Estados-membro. Ao impor-se ao Direito estatal por força e exigência de sua natureza, deve ser absolutamente comum a todos os Estados, não podendo estes invocar razões de Direito Constitucional para abster-se de fazê-lo e nem exigir mecanismos diferenciados de internalizarão da norma.

Por sua vez, a primazia da norma comunitária decorre pela transferência, por parte dos Estados-membro, de certas parcelas de sua soberania em favor da Comunidade Européia ${ }^{19}$, apresentando-se em três níveis distintos:

\footnotetext{
14 No momento da elaboração deste trabalho, o Tratado de Lisboa ainda não foi ratificado, e, portanto, o Tratado da União Européia - TUE - e as normas dele decorrentes não possuem, ainda, o mesmo status jurídico do direito proveniente do Tratado da Comunidade Européia, considerado Direito Comunitário em sentido estrito.
}

15 BLECKMANN, Albert. Europarecht. Das Recht der Europäischen Gemeinschaft. 5., neubearbeitete Auflage. Köln-Berlin: Carl Heymanns Verlag, 1995, p. 415.

16 O termo "Tratados Constitutivos" abrange o Tratado da Comunidade Européia (Tratado de Roma) que cria a Comunidade Econômica Européia em 1957, os Termos de Adesão e os Tratados que o modificam ou complementam, tais como interpretados pelo Tribunal de Justiça das Comunidades Européias.

17 O "ativismo jurisdicional" do TJCE reiteradamente enfatizou a particularidade do projeto de integração europeu e do Direito Comunitário, e sua diversidade em relação a outras Organizaçôes Internacionais de cunho intergovernamental e perante o Direito Internacional Público clássico.

18 Regulamentos e Decisões formam o núcleo dos temas mais importantes de direito comunitário. Já as diretivas estão mais vinculadas à harmonização das legislações nacionais, e necessitam de um ato nacional de incorporação.

19 Segundo jurisprudência do TJCE, iniciada com o caso Costa/ENEL de 1964 e posteriormente reiterada através de inúmeras decisões no mesmo sentido 
a) não apenas o Direito Comunitário originário, mas também o derivado possui a prevalência perante o Direito nacional;

b) em relação a leis nacionais anteriores à norma comunitária, esta detém a primazia e revoga aquelas. Mas também leis nacionais posteriores à norma comunitária já editada não são válidas;

c) a primazia das normas comunitárias incide também sobre as constitucionais. Ou seja, o Direito Comunitário não necessita coincidir com as Constituições nacionais e nem pode ser avaliado por elas.

A reiterada imposição da primazia da norma comunitária sobre a nacional condensou-se na quase que inevitável afirmação, por parte do TJCE, da natureza constitucional do Tratado de Roma ${ }^{20}$. Independentemente da questão de saber se os Tratados Constitutivos possuem os requisitos funcionais e materiais que os possibilitem ser qualificados como sendo a Constituição da Comunidade Européia, o certo é que as disposições normativas constantes nos Tratados Constitutivos sobre o TJCE, os métodos por este empregados para o seu desempenho e os princípios gerais que consubstanciam o exercício de suas funções, são razões que justificam plenamente "o paralelismo ou equiparação que a doutrina efetua entre o Tribunal de Justiça das Comunidades Européias e a justiça constitucional nacional" ${ }^{21}$.

Tal questão, transferida ao terreno do controle jurisdicional do Direito Comunitário, pode ser formulada do seguinte modo: o TJCE é o intérprete máximo do sentido e extensão do TCE e da compatibilidade do direito comunitário derivado. Para manter a coesão do Direito Comunitário houve, ao longo de todo o processo de integração europeu, a renúncia, por parte dos Tribunais Constitucionais nacionais, do controle da constitucionalidade da norma comunitária, ou seja, da adequação do ordenamento jurídico comunitário às Constituiçōes nacionais. Em outros termos, o Direito Comunitário não necessita coincidir com as Constituições nacionais e nem pode ser avaliado por elas. Neste sentido, um exemplo paradigmático foi a posição adotada pelo Bundesverfassungsgericht $(B v e r f G)^{22}$, o qual com a sentença "Solange II", renunciou ao exercício de sua jurisdição constitucional enquanto (Solange) o Direito e o Tribunal de Justiça comunitário dispensarem o mesmo nível de proteção aos direitos fundamentais que a Lei Fundamental de Bonn (Grundgesetz) considera indisponível.

$\mathrm{O}$ denominado acquis communautaire (entendido como sendo o conjunto dos princípios de lealdade comunitária e da boa-fé) impõe aos Estados a aceitação do Direito Comunitário na sua íntegra, em seu atual estado de evolução e

20 Os Verdes contra o Parlamento Europeu, de 1986, na qual o TJCE afirmou que, "nem seus Estados membros e nem suas instituiçôes podem subtrair-se ao controle da conformidade de seus atos com a carta constitucional fundamental que é o Tratado de Roma"

21 DUARTE, Maria Luíza. A teoria dos Poderes Implícitos e a Delimitação de Competências entre a União Européia e os Estados-membro. Lisboa : Lex, 1997, p.296 e 297.

22 Tribunal Federal Constitucional alemão. 
independentemente das suas fontes (e assim incluindo os princípios elaborados por via jurisprudencial, como é o caso do primado). Para tanto, grande parte dos Estados efetuou alterações em suas Constituições, incluindo uma cláusula de autorização geral para a delegação de poderes soberanos ou uma cláusula geral de limitação da soberania estatal ${ }^{23}$ :

Esta abertura constitucional possibilitou a criação de um quadro jurídico específico, que garantiu o cumprimento das regras destinadas a implementar o mercado comum, e posteriormente a união econômica e monetária, mesmo que à revelia circunstancial de alguns Estados-membro ou de conjunturas políticas e econômicas nacionais eventualmente contrárias à integração. Em sua trajetória, portanto, a UE consolidou-se como um exemplo único de processo de integração regional, que ao promover a livre circulação dos fatores produtivos e instituir um mercado comum, dotou-se, simultaneamente, de um arcabouço jurídico e institucional inédito na experiência constitucional e política internacional.

\section{Direito nacional, Intergovernamentabilidade e Integração no Mercosul}

Dificilmente o Tratado de Assunção pode ser interpretado como elemento ordenador de uma estrutura jurídica independente e autônoma tal como ocorreu na União Européia a partir do Tratado de Roma, tendo em vista as disposiçóes sobre a incorporação de normas aos sistemas jurídicos nacionais constantes no Protocolo de Ouro Preto e sua ênfase no sistema intergovernamental ${ }^{24}$.

A este respeito podem ser feitas algumas observaçôes. A primeira, relacionada à complexidade do procedimento de incorporação. Conforme está previsto, a norma editada pelos órgãos do Mercosul deve ser inicialmente incorporada de acordo com a sistemática constitucionalmente prevista em cada um dos Estadosparte para qualquer norma de Direito Internacional. A partir daí o procedimento se desdobra, com sua obrigação de informar a Secretaria do Mercosul do ato de incorporação, e posteriormente aguardar que a Secretaria comunique o anúncio da incorporação da norma pelos quatro Estados. Somente então é que cada Estado, individualmente, oficializa o ato por meio da publicação no respectivo Diário Oficial para que o início da vigência ocorra, simultaneamente, 30 dias depois da notificação pela Secretaria do Mercosul. Ou seja, este procedimento, por si só, é bem mais complexo do que o habitualmente previsto para os Tratados em geral.

Por outro lado, o art 42 POP determina expressamente a incorporação das normas, "quando necessário", aos ordenamentos nacionais. A ausência da necessidade

23 A Alemanha configura o exemplo mais elaborado deste sistema, no qual o art 24, I da Lei Fundamental possibilita a transferência de poderes soberanos para Organizaçōes Internacionais, e a própria integração européia está prevista no art 23.

24 O Protocolo de Ouro Preto (POP) de dezembro de 1994 deu início à implantação da União Aduaneira e estruturou jurídica e institucionalmente o Mercosul. 
de incorporação pode decorrer tanto do fato de que se trate de norma destinada regulamentar o funcionamento interno do Mercosul, quanto da constatação de que o Estado já trata do assunto em pauta em alguma norma nacional. Neste caso, instaura-se a incerteza quanto à simultaneidade e uniformidade da incorporação, na medida em que cada Estado poderá decidir, discricionariamente, sobre a necessidade ou não da incorporação de determinada norma.

Concluído o procedimento de incorporação da norma, os Estados-parte possuem distintas concepções quanto à sua posição hierárquica dentro dos respectivos ordenamentos jurídicos nacionais ${ }^{25}$. A Argentina adota o sistema supralegal, o qual prevê que o Congresso pode aprovar Tratados de Integração que deleguem competências e jurisdição a organizações estatais, sob a condição de reciprocidade e igualdade. Neste caso, as normas provenientes de tais organizações possuem hierarquia superior às leis federais, quando forem cumpridas as condiçóes de reciprocidade, igualdade e respeito pela ordem democrática e os direitos humanos ${ }^{26}$. O mesmo ocorre com a Constituição do Paraguai, em que uma cláusula permite a participação do Estado em uma estrutura supranacional, em "condiçōes de igualdade com outros Estados e que garanta a vigência dos direitos humanos, da paz, da justiça, da cooperação e do desenvolvimento nos âmbitos político, econômico, social e cultural"27. Apesar de ambos os países possuírem cláusulas de habilitação constitucional para a integração, o texto argentino é mais amplo que o paraguaio, pois prevê a situação hierárquica do direito derivado do Mercosul, o que não ocorre com a Constituição paraguaia. Por sua vez, Brasil e Uruguai, adotam o sistema da legalidade nas relações entre Direito Internacional e Direito nacional. Neste sentido, as normas internacionais (quaisquer que sejam) não possuem um status diferenciado, sendo que a norma posterior (qualquer que seja) derroga a norma anterior (mesmo sendo uma norma de origem internacional).

Desta forma, apenas Argentina e Paraguai possuem dispositivos constitucionais que viabilizam a abertura de suas estruturas jurídicas ao direito emanado do Mercosul. No entanto, o fato das duas Constituições adotarem o princípio da reciprocidade, exclui a adoção unilateral de medidas destinadas à incorporação automática das normas Mercosul e de seu status hierárquico privilegiado, se os outros Estados-membro do bloco não o fizerem. Tanto Brasil quanto Uruguai mantém mecanismos constitucionais defasados em relação às necessidades de um direito da integração, Argentina e Paraguai não se utilizam de seus próprios dispositivos constitucionais se não houver a devida reforma constitucional nos demais Países. Decorrente desta situação encontra-se o baixo índice de incorporação da normativa Mercosul e, portanto, o não cumprimento das regras destinadas a implementar o processo de integração, causando, consequentemente, falta de

25 Como sua adesão da Venezuela ainda não é definitiva, não será considerada membro pleno neste artigo.

26 Artigos 75 e 22 da Constituicao Federal Argentina.

27 Artigo 145 da Constituicao do Paraguai 
efetividade e um impacto extremamente negativo à eficácia política e econômica do Mercosul28.

Por sua vez, todos os Estados-parte mantém intactos seus sistemas de controle da constitucionalidade da norma internacional, e, por conseguinte também, da norma comunitária. Neste sentido, não é efetuada qualquer distinção entre as normas de origem internacional e as de origem comunitária. Permanecem, portanto, dois tipos de controle de constitucionalidade, o concentrado e o difuso. Desta forma, tanto as Cortes Supremas, quanto os órgãos de primeira e segunda instancias, podem manifestar-se sobre suposta inadequação da norma Mercosul às Constituições nacionais. Neste caso, a manutenção do sistema difuso é particularmente problemática. Considerando, no curso de um processo, que determinada norma Mercosul seja inconstitucional, qualquer órgão judiciário suspende a aplicação da norma até a manifestação definitiva do órgão jurisdicional de recurso ${ }^{29}$. Instaura-se assim uma situação de descompasso jurídico entre os Estados, pois uma norma Mercosul seria considerada constitucional (aplicável) em um Estado e inconstitucional (inaplicável) em outro.

As dificuldades doutrinárias e jurisprudenciais decorrentes do Direito Mercosul podem ser sintetizadas nas contradições surgidas em duas sentenças de diferentes órgãos jurisdicionais brasileiros. No primeiro caso, o Superior Tribunal de Justiça - STJ qualificou como constitucional um dispositivo do Mercosul inicialmente considerado inconstitucional pelos juízos de primeiro e segundo grau. Na sentença proferida, o STJ argumentou que a suspensão judicial da importação de arroz argentino e uruguaio, garantida pelo acordo de livre comércio do Mercosul, estava provocando duas importantes conseqüências: a perda de credibilidade da política externa brasileira e, principalmente, o comprometimento da consolidação do Mercosul $^{30}$. Neste caso, ficou evidente a percepção de que, mesmo em um sistema intergovernamental, existe a necessidade de mecanismos diferenciados de articulação das ordens jurídicas.

Contudo, em outra ocasião, o Supremo Tribunal Federal ao examinar a recepção e aplicabilidade de uma norma do Mercosul, manifestou-se no sentido de que não existe um verdadeiro direito comunitário, "já que as convenções celebradas sob a égide do Mercado Comum do Sul qualificam-se no presente estágio de seu desenvolvimento institucional, como instrumentos regionais de direito internacional público" ${ }^{31}$. Ou seja, o problema, além do sistema intergovernamental em si, reside no fato de que setores da doutrina e jurisprudência não admitem

28 Sobre a incorporação da normativa Mercosul, ver CRISTINI, M; AMAL, M. Investimento Direto Externo no Mercosul. O papel da Europa. Rio de Janeiro: Konrad Adenauer Stiftung, 2006.

29 A maior parte dos sistemas sul americanos de controle difuso de constitucionalidade concede ao juiz singular a capacidade de suspender a aplicação da norma ao caso concreto, caso a considere inconstitucional.

30 STJ. Petição No 1273/RS. Registro No 2000/0040618-0.

31 STF AgRg 8.279/98. Voto do Relator, Ministro Celso Mello. 
a especificidade do Direito do Mercosul como um Direito Comunitário ou da Integração, e, neste sentido, traduzindo juridicamente um novo tipo de formatação das relações entre Estados.

\section{Instituições, Soberania e Integração: algumas considerações}

$\mathrm{Na}$ articulação entre os ordenamentos jurídicos nacionais e o comunitário europeu, a renúncia ao controle da constitucionalidade das normas comunitárias implicou, indiretamente, na renúncia à tese da soberania absoluta do povo tal como expressa no Poder Constituinte. Ocorreu, portanto, um deslocamento da fonte última do poder do Estado, não mais expresso nos preceitos constitucionais internos, mas baseado num conjunto normativo supranacional, o qual não possui (ainda) um mandato popular explícito para atuar de modo a contrariar as Constituiçóes nacionais. Por sua vez, a aplicabilidade imediata da norma comunitária, vincula não apenas as instituições do Estado, mas também as pessoas privadas. Ou seja, existe um conjunto de normas que não emana exclusivamente do Estado e nem depende de sua vontade para vincular seus destinatários. Por outro lado, a primazia do Direito Comunitário e o caráter constitucional dos Tratados Constitutivos, constantemente reafirmados pela jurisprudência do próprio TJCE, alçaram-no à condição de Tribunal Constitucional supranacional. Portanto, se existe uma Constituição supranacional e um órgão competente para interpretá-la e impor tal interpretação aos destinatários, caracteriza-se a submissão dos órgãos do Estado a uma fonte de poder que lhes é, efetivamente, exterior.

Por sua vez, a instabilidade jurídica do Mercosul reflete a diversidade de seus objetivos, em especial a implantação de um verdadeiro Mercado Comum, com os instrumentos institucionais meramente intergovernamentais, típicos de uma simples Zona de Livre Comércio, sem maiores ambiçôes integracionistas e sem nenhum tipo de mecanismo de "soberania compartida". Ao manter o status quo constitucional baseado na soberania nacional, este modelo tem provocado uma série de problemas e impasses, tornando-se clara a necessidade de dispositivos constitucionais específicos que permitam a abertura da ordem jurídica nacional ao direito da integração.

O conceito tradicional de soberania do Estado sofreu profundas alterações desde o fim da Primeira Guerra Mundial. Em especial, a soberania externa foi subordinada às regras do Direito Internacional, caracterizado pela "igualdade soberana entre Estados", porém sujeitos às regras válidas para todos. Neste sentido, a soberania adquire um significado de independência em relação à outros Estados, porém de dependência quanto às regras comuns $s^{32}$. Nesta concepção, a transferência voluntária de parcelas de soberania a organizações internacionais é perfeitamente possível, na medida em que não é mais viável a autonomia ilimitada do Estado.

32 DOERING, Karl. Allgemeine Staatslehre. Heidelberg : C.F.Müller, 2004, p. 117. 
Mais complexa é a situação no interior dos Estados, caracterizada pela soberania interna. $\mathrm{O}$ entendimento relacionado à superioridade das normas constitucionais sobre as internacionais de qualquer natureza e a manutenção de um espaço jurídico impermeável ao exterior, não decorre de uma posição dogmática relacionada ao primado absoluto da soberania do Estado, tal como no século XIX. Aqui, a questão está centrada no conceito de legitimidade do ordenamento jurídico, já que o povo, detentor da soberania interna, se expressa pelo Poder Constituinte e de seus representantes eleitos para mandatos legislativos específicos.

No caso dos Estados-membro da UE, resta a questão de saber se atualmente a unidade do poder do Estado já não foi em tal medida esgarçada no processo supranacional de integração, que se torna necessário indagar por uma nova configuração estatal. No entanto, tal como demonstrado pelo debate sobre a Constituição Européia, a diluição total da soberania ainda está longe de ser pacífica. O exemplo do Mercosul demonstra que mesmo no modelo intergovernamental, existe a necessidade de um sistema jurídico com características diferenciadas. A atual concepção de soberania interna e externa é insuficiente para promover a integração supra-estatal e inserir sua ordem normativa dentro da dogmática jurídica dos Estados-parte. A manutenção do paradigma constitucionalista do inicio do século XX, e a ênfase na soberania interna, tem ocasionado o descompasso entre as condicionantes da integração e um quadro jurídico defasado.

Qualquer ordem econômica baseada no mercado está indissociavelmente vinculada a um quadro jurídico confiável, que garanta contratos e proteja direitos ${ }^{33}$. Nesta perspectiva, a importância do sistema jurídico no âmbito de processos de integração regional é decisiva, na medida em que seu desenvolvimento econômico, político e social, depende fortemente das diretrizes apresentadas pelas normas destinadas a implementar a integração. Sob a ótica da eficácia de seu ordenamento jurídico para alcançar os objetivos desejados, cada processo de integração possui um componente de ordem política e não apenas jurídica. Neste caso, o debate sobre soberania e integração deve incluir, também, o debate sobre a manutenção da atual configuração dos Estados e os rumos de sua eventual transformaçãa.

Recebido em 19 de maio de 2008 Aprovado em 20 de janeiro de 2009

\begin{abstract}
Based on the case study of European Union and the Mercosur, the purpose of the present paper is to analyze and discuss certain issues emerging from the articulation of a normative framework stemming from the join organs of integration with national juridical orderings based on the principle of state sovereignty.
\end{abstract}

33 HERDEGEN, Matthias. Internationales Wirtschaftsrecht. München : C.H. Beck, 2007, p. 86. 


\section{Resumo}

Baseado no estudo de caso da União Européia e Mercosul, o objetivo deste artigo é analisar certas questões decorrentes da articulação do quadro normativo oriundo dos órgãos conjuntos de integração regional, com as ordens jurídicas nacionais baseadas no princípio da soberania do estado.

Palavras-chave: Integração regional. Instituições. Soberania. Efetividade jurídica. Key wods: Regional Integration. Institution. Sovereignty. Legal effectiveness. 